\title{
ANÁLISE ESPACIAL DO RURAL NO MUNICÍPIO DE MONTES CLAROS-MG
}

\author{
Ana IvaniaAlves FONSECA ${ }^{1}$ \\ Marcela Alves FONSECA2 \\ Lilian Damares de AlmeidaSilva FREITAS ${ }^{3}$ \\ Ramony Maria Da Silva Reis OLIVEIRA \\ Cássio Alexandre da SILVA
}

\section{Resumo}

A análise espacial é um elemento importante para entendermos a formação e a lógica de produção em um município. O espaço geográfico é dinâmico, mutável e passa por inúmeras transformações ao longo do tempo. Desta forma, o desenvolvimento rural é um conceito essencial, pois, introduz novas práticas sociais e tecnologias no espaço rural de forma sustentável proporcionando a manutenção do agricultor no campo e o aumento da produtividade. O objetivo desse estudo é analisar a organização espacial e sua dinâmica com a agricultura camponesa ou familiar no município de Montes Claros. Os resultados preliminares apontam para um rural que mantém um tradicionalismo na sua forma de produção, o que propicia a manutenção de diversas famílias no campo.

Palavras-chave: Análise espacial. Espaço geográfico. Município.

\section{Abstract}

\section{Space analysis of the rural in the municipality of Montes Claros-MG}

The spatial analysis is an important element to understand the formation and its logic of production in a municipality. Geographic space is dynamic, changeable and goes through many transformations over time. This work intends to make an analysis of the rural area of the municipality of Montes Claros. In this way, rural development is an essential concept, as it introduces new social practices and technologies in the rural space in a sustainable way, providing, the maintenance of the farmer in the field and the increase of productivity. The purpose of this study is to analyze spatial organization and its dynamics with peasant or family agriculture. This study is in progress. The preliminary results are pointing to a rural one that maintains a traditionalism in its form of production, and this production is that it propitiates the maintenance of several families in the field.

Key words: Spatial analysis. Geographic space. Municipality.

\footnotetext{
1 Professora do Departamento de Geociências/Unimontes. E-mail: anaivania@gmail.com

2 Universidade Estadual de Montes Claros. E-mail: marcela.alvesfonsec@hotmail.com

3 Pesquisadora do Centro de Estudos de Convivência com o Semiárido - CECS/Unimontes.

E-mail: liliandamaress@gmail.com

4 Professora do Instituto Federal de Educação do Norte de Minas Gerais.

E-mail: ramonyeduc@yahoo.com.br

5 Docente do Programa de Pós-Graduação em Geografia- PPGEO/ UNIMONTES.

E-mail: cassioas27@gmail.com
} 


\section{INTRODUÇÃO}

Percebemos que o rural, nos últimos 60 anos, foi intensamente mecanizado em nome de uma modernidade que não levou em conta inúmeros atores sociais presentes no rural onde viviam, vivem e cultivam as terras há várias gerações. A mudança na forma de produção alterou significativamente o espaço rural. A análise desta categoria desde sua origem tem sido objeto do estudo da geografia. O espaço geográfico é dinâmico, mutável e passa por inúmeras transformações ao longo do tempo. Ao estudarmos especificamente o espaço rural vemos um espaço no qual o desenvolvimento segue duas linhas, uma do tradicionalismo representado por famílias que se mantêm secularmente nessas áreas e que mesmo com a modernização concentra o seu trabalho no modelo familiar, baseado na utilização de poucas técnicas e na venda direta para o consumidor. A outra linha é a da modernização que chegou após a década de $1970 \mathrm{com}$ a Revolução Verde e veio massificando as pequenas propriedades rurais. Dessa forma, estudo do desenvolvimento rural faz-se necessário para entendermos como o processo e a atualidade convergem na organização desse espaço.

O desenvolvimento rural deve ser visto como uma possibilidade de transformação, mas essa transformação não pode interferir de forma nociva no modo de vida rural e na sua organização, tem que se levar em conta a economia da sociedade como um todo, de forma que aumente o potencial produtivo e, também, criativo dos moradores do campo, promovendo a igualdade social entre campo e cidade.

Costabeber e Caporal (2003) propõem uma análise multidimensional da sustentabilidade rural, para que o processo de desenvolvimento rural seja sustentável e expresse mudança não somente no aspecto quantitativo (mudança no tamanho), como também uma expansão nos aspectos qualitativos para que haja ampliação das qualidades e oportunidades como condição para maiores ganhos social, econômico, ambiental, político e cultural, sem abrir mão da ética da solidariedade. Nesse raciocínio, o município de Montes Claros vem apresentando um dinamismo na sua organização rural. Para Fonseca (2012), a ocupação do município de Montes Claros desenvolveu-se com base em três momentos: a colonização, por volta do século XVII - com a chegada a região dos bandeirantes, considerados na época, os desbravadores do sertão e adquiriram terras, entre eles, o bandeirante Antônio Gonçalves Figueira, que constituiu a fazenda dos Montes Claros, que mais tarde se tornou o Arraial das Formigas. Em 1831, passa à categoria de Vila de Montes Claros e em 03 de junho de 1857 a vila foi elevada à categoria de cidade de Montes Claros. A chegada da linha férrea em 1926, que ligou a cidade à capital mineira, permitiu um intercâmbio de mercadorias e pessoas, propiciando um dinamismo intenso para a época. $E$, num terceiro momento, na década de 1950 com a criação da Superintendência de Desenvolvimento do Nordeste - Sudene, que concentrou na cidade os principais órgãos governamentais para a implantação do distrito industrial para região, bem como, a sede da Companhia de Desenvolvimento do Vale do São Francisco e Parnaíba Codevasf, esse órgão tinha como objetivo desenvolver a região que estava inserida na bacia do São Francisco, na porção norte do Estado de Minas Gerais.

Esses elementos propiciaram um crescente desenvolvimento do município de Montes Claros e veio a fortalecer o processo histórico de desenvolvimento de toda a região. Considerado um desenvolvimento tardio com relação às demais regiões mineiras, o Norte de Minas, passou por um processo de ocupação de suas áreas rurais de forma desordenada e apesar das características climáticas adversas, as grandes fazendas de gado se organizaram em toda a região. O rural desses municípios possui características bastante diversas, no qual grandes fazendas de criação de gado ou o grande plantio de fruticulturas contrastam com pequenas propriedades baseadas na 
agricultura familiar. Nas últimas décadas, as pequenas propriedades vêm se fortalecendo, principalmente, a partir da aquisição do Programa Nacional de Fortalecimento da Agricultura Familiar - Pronaf.

Ao longo da história, o produto mais comercializado foi o gado de corte. Essa foi e ainda é uma forte dinâmica econômica dos municípios.

Para Oliveira (2000, p. 67),

Este panorama econômico se mantém por longo período de tempo sem que ocorressem significativas alterações. Só a partir do final da década de 1950, com a criação da SUDENE, é que a região passa de novo a apresentar transformações significativas na sua estrutura produtiva. (OLIVEIRA (2000, p. 67),

Nesse contexto, os municípios Norte Mineiros não se integraram totalmente ao modelo desenvolvimentista pensado pelo governo, mas se manteve com certa tradicionalidade nas suas formas de fazeres e saberes. As comunidades se organizaram de formas diversas, ora se integrando ao mercado, ora se organizando internamente, fortalecendo o modelo familiar de produção da agricultura. Do ponto de vista econômico, os pequenos e médios agricultores familiares se veem circundados por médias fazendas de criação de gado de corte. Existem poços artesianos com documentação, mas os agricultores também relatam dificuldades com burocracias para legalização e implantação de melhorias no meio rural, além de altos impostos que são pagos na confiança que irão trazer avanços para o ambiente em que vivem.

Dessa forma, o objetivo desse estudo é analisar a organização espacial e sua dinâmica com a agricultura camponesa ou familiar. Utilizamos como metodologia a revisão bibliográfica, fizemos também visitas in loco planejadas através de reuniões nas sedes de associações comunitárias. Em cada reunião foi feita uma coleta de dados e o diálogo com os moradores das comunidades, e, para o levantamento de dados aplicamos a metodologia de diagnóstico rural participativo que possibilitou o levantamento dos principais problemas e potencialidades das comunidades e do município.

\section{A ORGANIZAÇÃo dO ESPAÇO RURAL E A REGIÃO DO NORTE DE MINAS}

Nas últimas décadas, a crise da agricultura convencional tem levado à busca de outros modelos de desenvolvimento para a agricultura. Assim, observam-se, no Brasil, avanços nos estudos rurais sobre as formas familiares de produção e sobre suas relações com os processos de desenvolvimento rural.

Dessa forma, a projeção social e política da agricultura familiar no país, nos últimos anos, podem ser compreendidas como expressão de reconhecimento e legitimação, o que demandou ampla capacidade de mobilização, encetadas através dos movimentos sociais no campo, protestos e ações dos próprios agricultores. Esses movimentos tiveram como resposta as políticas governamentais cada vez mais identificadas com o território rural (FONSECA, 2012). A região do Norte de Minas ${ }^{5}$ vem passando por uma transição espacial, sentida principalmente no espaço rural, na

\footnotetext{
5 A mesorregião do Norte de Minas é uma das doze mesorregiões do estado brasileiro de Minas Gerais. É formada pela união de 89 municípios, agrupados em sete microrregiões.
} 
qual, ora apresenta uma mecanização efervescente, ora observamos uma forma tradicional de se trabalhar a terra, ora o agronegócio divide espaço com esse tradicionalismo.

O Norte de Minas Gerais é uma vasta região que compõe o estado, e se encontra numa interface entre o cerrado e a caatinga nordestina, no município de Montes Claros, especificamente, essas características são muito nítidas, a paisagem é um misto entre os dois biomas e isso reflete no modelo de produção, pois, é muito comum encontrar elementos da caatinga inseridos com os elementos do cerrado e também o contrário, assim, esse perfil compõe a região e o município de Montes Claros como uma paisagem diferenciada do restante do estado, veja a figura 1.

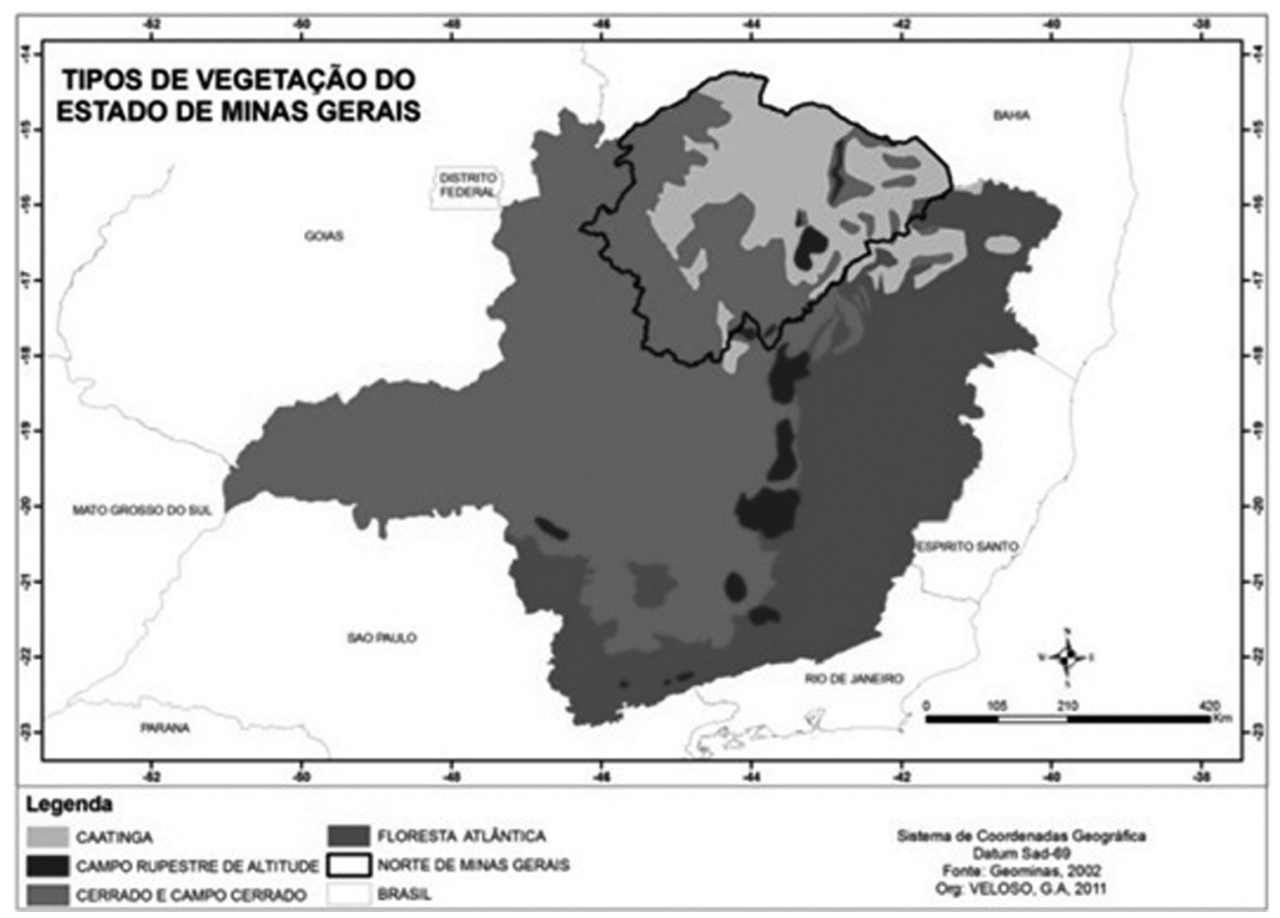

Figura 1 - Mapa de Minas Gerais - Vegetação

Fonte: Fonseca, A. I. A, 2012

A paisagem ao longo da história foi um fator importante, pois dada sua semiaridez, as fazendas de criação de gado de corte se tornaram muito comuns, bem como as pequenas propriedades, nas quais se praticava a agricultura para o autoconsumo. Essas características climatológicas proporcionaram ao município se inserir no polígono da seca6 ${ }^{6}$. Essa inserção foi um dos principais modificadores dos

\footnotetext{
${ }^{6}$ A Lei $175 / 36$ (revisada em 1951 pela Lei 1.348) reconheceu o Polígono das Secas como a área do Nordeste brasileiro composta de diferentes zonas geográficas com distintos índices de aridez e sujeita a repetidas crises de prolongamento das estiagens. Acessado em: http:// www.camara.gov.br/sileg/integras/446748.pdf
} 
espaços no município e proporcionou um crescente desenvolvimento que fortaleceu o processo histórico de toda a região. O relevo é outro elemento importante na configuração do espaço do Norte de Minas, segundo o CHAGAS (1999) é marcado pela presença da Serra do Espinhaço, que atravessa toda a região central na direção Norte/Sul, que se caracteriza por topos de serras, chapadas e planícies, apresentando altitudes de 750 a 1200 m, com extensas áreas de terras planas ou levemente onduladas, de solos geralmente pobres e profundos com coberturas vegetais constituídas, pelo cerrado e a caatinga o que permitiu o desenvolvimento de uma policultura adaptada a esses dois tipos de vegetação. Nos anos 1970 e 1980, grande parte dessa região teve suas vegetações substituídas pelas pastagens artificiais e pela monocultura de eucalipto (CHAGAS, 1999, p. 38 apud FONSECA 2012).

A vulnerabilidade dessa região é causada pelos seus aspectos climáticos, pois cerca de 8 (oito) meses do ano está sobre o rigor da seca tendo nos últimos anos aumentado esse período. A partir da década de 1960 a região se integrou ao modelo baseado na Revolução Verde, acreditava-se que através da mesma seria possível garantir a segurança alimentar, entretanto, ao se analisar o modelo de produção proposto pela Revolução Verde, fica claro que este foi um projeto idealizado por outros países e implantado no Brasil, cujo objetivo era a alta produtividade visando grandes mercados, acima de questões como a segurança alimentar de fato, ou mesmo a sustentabilidade.

Os modelos de produção tradicionais passaram por esse processo de mudança sem uma efetiva análise dos atores locais, que se inseriram no novo modelo sem a devida orientação. O resultado disso foi que muitos não se integraram totalmente, mas adquiriram incipientemente algumas técnicas. Percebe-se um processo que Wanderley (2004, p. 46) chama de "[...] ruptura/continuidade permanece como guia para a compreensão dos processos de transformação, nos casos em que, efetivamente, se afirme a presença de uma agricultura familiar.". No Norte de Minas as rupturas entre os modelos rurais vêm se acentuando principalmente entre o tradicionalismo e a modernidade.

\section{O ESPAÇO RURAL DO MUNICÍPIO DE MONTES CLAROS}

A origem das cidades no Norte de Minas, segundo Gomes (2007), remete sempre aos locais de descanso dos tropeiros que utilizavam o mesmo espaço para seu descanso, quando ali passavam, com a cidade de Montes Claros a história não foi diferente. Nesses locais, normalmente formavam-se as primeiras feiras para a troca de produtos. A cidade de Montes Claros destaca-se por ter maior dinâmica regional e por possuir todas as condições de infraestrutura necessárias para tal destaque, condições essas não oferecidas, até o momento, por outras cidades da região.

Leite (2003, p. 124) explica essa dinâmica assim:

A infra-estrutura criada para a industrialização passa a ser utilizada por outros setores econômicos. Assim, embora o ritmo de desenvolvimento tenha diminuído para o setor secundário, o que se percebe é que, Montes Claros, nas últimas décadas tem-se firmado como centro comercial de prestação de serviços principalmente no que se refere ao setor educacional e saúde. 
Em termos numéricos Montes Claros se insere em uma mesorregião com aproximadamente 1.686.913 habitantes (IBGE, 2010), e que, de acordo com o Censo Agropecuário (2006), possui 18.702 pequenos estabelecimentos agrícolas, o que corresponde a uma área de 38.336 hectares, sendo esses os responsáveis por boa parte do abastecimento do município, o Mercado Municipal possui destaque como centro de comercialização e socialização (FONSECA, 2012). O espaço rural tem se apresentado dinâmico nesse município, com áreas de mecanização intensas limítrofes com áreas em que a produção obedece modelos tradicionais de trabalhar a terra. Dada essa variedade o conceito de agricultura familiar no Brasil é difícil de ser trabaIhado e é relativamente recente, pois só a partir de 1990 que as políticas públicas efetivamente trabalharam com este conceito. O agricultor familiar, antes mesmo de ser assim conhecido, empiricamente, dizia respeito apenas àquele de pequena produção, e até mesmo se utiliza o termo camponês.

A partir da década de 1990, ocorreu um crescente interesse na agricultura familiar, desencadeado por movimentos sociais e organizações de defesa dos interesses dos trabalhadores do campo, que reivindicaram, junto ao governo, a criação de políticas públicas voltadas para a agricultura familiar. Com a criação do Ministério do Desenvolvimento Agrário (MDA) e da Secretaria de Agricultura Familiar (SAF), foram criadas linhas de crédito específicas para a agricultura familiar através do Programa Nacional de Fortalecimento da Agricultura Familiar (Pronaf). Esse novo modelo acirrou as rupturas entre os modelos existentes, intensificando no rural uma mudança rápida transformando, em alguns casos, o espaço e seu modo de produção. Ao observar a figura 2 vemos que a maneira tradicional se mantém em muitas áreas. O plantio consorciado entre as culturas e o meio ambiente é uma realidade em muitas pequenas propriedades.

Segundo os agricultores a organização rural perpassa pelas associações e os sindicatos rurais, são nas reuniões que as discussões e os projetos, bem como, o acesso às linhas de crédito se tornam possíveis. Destaca-se também a união entre as pessoas que contribui para a permanência nas comunidades. Nos locais em que as pessoas têm maior engajamento na associação, os resultados alcançados são satisfatórios e o acesso à informação é maior. Em contrapartida, nas comunidades onde não há envolvimento das pessoas ou não há uma liderança interessada nas necessidades da comunidade, a associação só funciona como intermediária para o acesso aos programas e políticas do governo. A organização da produção tem uma base na ancestralidade, onde o modelo de produzir no espaço era com respeito a natureza e o plantio era feito de forma consociada para que a terra mantivesse o equilíbrio e que os nutrientes se agregassem ao solo, permitindo a produção anual de diversos produtos, tais como: milho, abóbora, quiabo, frutas, etc. Esse modelo é muito comum na região como pode ser observado na figura 2 .

Entretanto, encontramos contradições nos modelos mesmo dentro da agricultura familiar, alguns agricultores plantam sem agrotóxicos, outros utilizam a prática familiar que segue o modelo convencional, com o uso, mesmo que pequeno, de agrotóxicos e insumos químicos. Na atualidade, os produtores já demonstram ter um novo olhar para os produtos orgânicos que vêm, cada vez mais, ganhando espaço e valor de mercado. Por isso, eles já têm ciência de que precisam recriar um ambiente favorável para entrar nesse nicho. Partindo dessa percepção, a recuperação das águas é fundamental para que, num futuro próximo, eles consigam inserir-se nesse modelo de produção. 


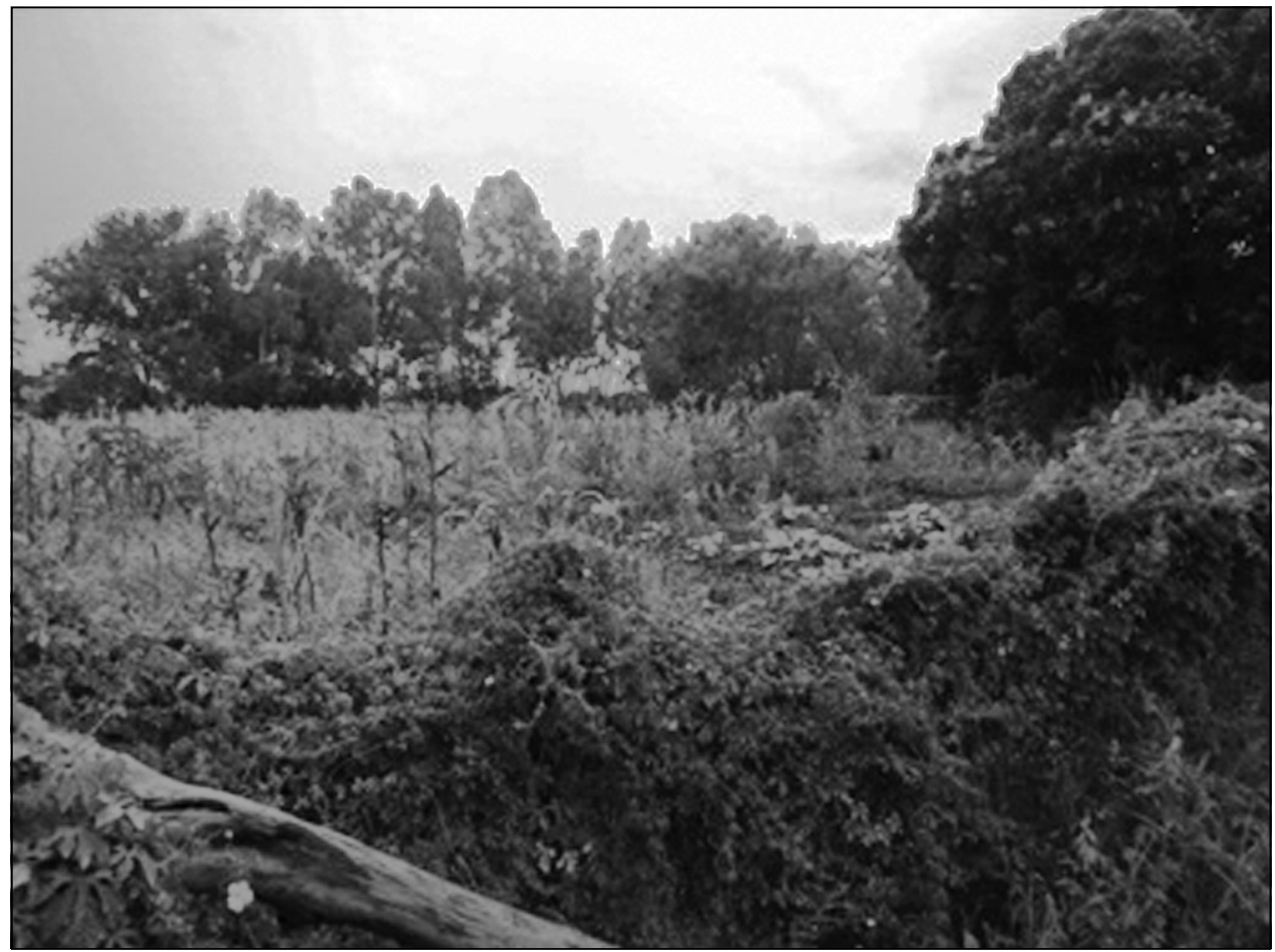

Figura 2 - Plantio consorciado

Autora: FONSECA, M. A. (2016)

A organização espacial no município se dá de forma a refletir a modernidade e a tradicionalidade, verificando-se elementos desses dois modelos. As áreas contrastam com fazendas de criação de gado, grandes plantios de fruticultura, especialmente, a banana. Com áreas de uma policultura diversa com base nos hortifrutigranjeiros que são produzidos principalmente nas pequenas propriedades e que são vendidos nas feiras. Esse processo de plantio e vendas diretas teve um aporte financeiro a partir das políticas públicas, acentuadas principalmente pelo Pronaf, após os anos 2000. As formas de moradia nas pequenas propriedades também mudaram nestas últimas décadas, com a construção de casas bem estruturadas, possuindo diversos eletrodomésticos onde a família tem acesso a quase todos os elementos da vida citadina. As comunidades e distritos que compõem o município vêm adquirindo maior dinamismo, com comércios diversos, escolas, postos de saúde, quadras poliesportivas se tornando minicentros locais. Em algumas comunidades, as reuniões de associações se tornam uma grande feira de vendas e trocas de produtos diversos. Mas essa organização mais dinâmica tem atraído a insegurança rural, onde é comum o registro de crimes diversos principalmente roubos às residências. As casas que outrora não ofereciam atrativos para esses crimes passaram a ter elementos de valor comercial como: eletrodomésticos, carros e motos, além de equipamentos usados no trabalho no campo. 
Percebemos que a agricultura familiar passa por um difícil consenso, pois dentro do rural encontramos níveis de uso do espaço diferenciados, temos desde os agricultores inseridos no mercado e com propriedades com uso intenso do solo, bem como aqueles que estão mais preocupados com o nível de alimentos e agrotóxicos que eles irão utilizar, o desenvolvimento está pautado na família e na natureza com a produção para o autosustento, ou seja, a venda dos produtos tem a lógica da natureza, vende-se o excedente.

\section{CONSIDERAÇÕES FINAIS}

Ao analisar o espaço rural é necessário que se observe suas potencialidades, oportunidades, bem como seus entraves e suas rupturas. Essas dimensões podem nos aproximar de uma escrita mais realista de suas populações e do cotidiano rural refletido na sua organização. Nesse sentido, o município aqui analisado possui sua singularidade na ancestralidade de sua história, mas, as transformações advindas da modernidade configuram como algo que sobrepõe esse tradicionalismo.

Ao tratar especificamente do município, ocorre uma organização em nível social que, em grande parte, é propiciada pelas associações, que possibilitam aos agricultores não mais serem concorrentes entre si, mas parceiros de produção. Com isto, conseguem vender seus produtos com um preço mais justo e rentável. É inerente a essas comunidades a preocupação ambiental, ao longo da última década esta inquietação vem implementando ações de recuperação das áreas degradadas. 0 tradicionalismo mantido no campo foi um fator de proteção ambiental e de suas populações, percebemos um número ainda significativo de pessoas morando e trabalhando nesse espaço.

Por fim, mesmo com a agregação de valor, a agricultura familiar e os modelos de produção passaram por processos de mudanças sem uma efetiva análise dos atores locais, mas esses atores vêm se adaptando, sem perder, contudo, o seu modo de fazeres e saberes seculares. Mesmo não se inserindo de forma integral ao modelo dito moderno, desenvolveram técnicas que permitiram uma produção de qualidade e com valor de mercado.

\section{REFERÊNCIAS}

COSTABEBER, J. A.; CAPORAL, F. R. Possibilidades e alternativas do desenvolvimento rural sustentável. Agricultura familiar e desenvolvimento rural sustentável no Mercosul. Santa Maria: Editora da UFSM/Pallotti, 157-194. 2003

CHAGAS, Ivo das. Estrutura e funcionamento do Bioma Cerrado. In: Caderno Geográfico. Montes Claros/MG: Editora da UNIMONTES, 1999, ano III, v. 3.

FONSECA. A. I. A. Agricultura Familiar como Sustentabilidade: Estudo de Caso do Planalto Rural de Montes Claros/MG. 2012.181 f. Tese de Doutorado em Geografia. Instituto de Geociências e Ciências Exatas - Universidade Estadual Paulista Júlio de Mesquita Filho, Rio Claro. 2012. 
GOMES, F. S. Discursos contemporâneos sobre Montes Claros: (re) estruturação urbana e novas articulações urbano-regionais. 2007. $181 \mathrm{f}$. Dissertação (Mestrado em Arquitetura e Urbanismo) - Núcleo de Pós-graduação em Arquitetura e Urbanismo da Escola de Arquitetura, Universidade Federal de Minas Gerais, Belo Horizonte, 2007.

IBge. instituto DE Geografia e eStatístiCA. Censo Demográfico. 2010. https:/ /ww2.ibge.gov.br acessado em 17/04/2018

OLIVEIRA, M. F. M.; RODRIGUES, L. (Org.). Formação econômica e social do Norte de Minas. Montes Claros: Ed. Unimontes, 2000.

PEREIRA, A.M. Cidade Média e Região: O Significado de Montes Claros no Norte de Minas Gerais Pereira. Tese de doutorado - Instituto de Geografia, Universidade Federal de Uberlândia: UFU, Uberlândia, 2007.

PRONAF. Programa Nacional de Fortalecimento da Agricultura Familiar. Disponível em: https://www.sicredi.com.br/html/para-seu-agronegocio/credito/pronaf/ Acesso em: 22/ $07 / 2017$.

LEITE, M. E.; PEREIRA. A. M. A expansão urbana de Montes Claros a partir do processo de industrialização. In. PEREIRA, A. M.; ALMEIDA, M. I. S de (Org.). Leituras geográficas sobre o Norte de Minas Gerais. Montes Claros: Unimontes, 2004, p. $33-51$.

SILVA. L. D. A. Agricultura Familiar:Uma Abordagem Sobre a Multifuncionalidade na Comunidade Planalto Rural Município de Montes Claros - MG. Monografia (Curso de Graduação em Geografia) - Centro de Ciências Humanas, Universidade Estadual de Montes Claros, Montes Claros, 2012, 41 p.

WANDERLEY, M. de N. B. Agricultura familiar e campesinato: rupturas e continuidade. Texto preparado para a Aula Inaugural do primeiro semestre de 2004 a ser ministrada no CPDA/UFRRJ. Disponível em: http://r1.ufrrj.br/esa/art/200310042-061.pdf. Acesso em 20 de agosto de 2015.

\section{SITES CONSULTADOS:}

Portal do IBGE: http://www.ibge.gov.br/home/

Portal do MDA: http://www.mda.gov.br/

http://www.camara.gov.br/sileg/integras/446748.pdf

https://cidades.ibge.gov.br/v4/brasil/mg/montes-claros/panorama 